\title{
Editorial
}

\section{Neurofibromatosis 1 Somatic Mutation Triggering Cellular Apoptosis to Prevent Neurofibromatosis 1 Progression}

\author{
Vincent M. Riccardi, MD, MBA* \\ The Neurofibromatosis Institute, 54 I5 Briggs Avenue, La Crescenta, CA 91 2 I 4, USA \\ "Corresponding author \\ Vincent M. Riccardi, MD, MBA \\ The Neurofibromatosis Institute, 5415 Briggs Avenue, La Crescenta, CA 912 I4, USA; E-mail: riccardi@medconsumer.com
}

Article information

Received: February 26 ${ }^{\text {th }}, 2020$; Revised: March 28 ${ }^{\text {th }}, 2020$; Accepted: May II ${ }^{\text {th }}, 2020 ;$ Published: May $13^{\text {th }}, 2020$

Cite this article

Riccardi VM. Neurofibromatosis I somatic mutation triggering cellular apoptosis to prevent neurofibromatosis I progression. Neuro Open J. $2020 ; 7($ ): el-e2. doi: I0.I7I40/NOJ-7-e0I I

$\mathrm{P}$ ersons with ordinary, prototypical Neurofibromatosis 1 (NF1) are born with a germinal/zygotic mutation at the NF1 locus on the long arm of chromosome 17 (17q) present in all of their cells. An NF1 germinal mutation is the "first hit," accounting for haploinsufficiency at the NF1 locus. The NF1 somatic mutation is the "second hit," accounting for diploinsufficiency (deranged or lost function of both alleles) at the NF1 locus. The NF1 somatic mutation occurs in a variety of somatic (i.e., non-germinal) cells, including, and especially the schwann cells (SC). I suggest that NF1 haploinsufficiency provides the conditions for the SC (and other cells) to develop NF1 diploinsufficiency rather than NF1 diploinsufficiency developing independently of the conditions in which it originates. In either case, imagine a viral analogue with an apoptosis trigger held in abeyance unless an NF1 somatic mutation occurs in the presence of an NF1 germinal mutation or whole gene deletion. That is, instead of altering the feature, for example, decreasing neurofibroma size and symptoms with MEK inhibitors, I herein suggest an approach to preventing certain NF1 features, keying off the fact that almost NF1 features involve somatic mutation of the cell's NF1 wild type (WT) allele.

The NF1 phenotype, that is, the NF1 syndrome, has many elements, not all with the same "causal relationship" to NF1 genotype. NF1 features are elements closest in causal proximity to the genomic disturbance, for example, neurofibromas or vertebral dysplasia. ${ }^{1}$ NF1 consequences, derived from NF1 features, include atypical neurofibromas and spinal scoliosis. ${ }^{1}$ NF1 complications, derived from NF1 consequences, include neurofibrosarcoma and spinal cord compression. ${ }^{1}$ Respecting the publication of F.L. Rice and colleagues, ${ }^{2}$ there is also the matter of the precursor of the NF1 feature. Their article emphasizes the importance of NF1 syndrome elements that are precursors to the syndrome's characteristic features. Specifically, they describe a precursor to the NF1 cutaneous neurofibroma (cNF). One important question the article raises is the presence or timing of the NF1 somatic mutation with regard to the development of the NF1 feature. Does the NF1 somatic mutation derive the precursor or does the NF1 somatic mutation account for the conversion of the precursor to the feature? I expect that often it is the latter. Respecting this general type of reasoning, perhaps the NF1 syndrome progression could be reversed or stopped early on through genetic manipulation before elements of the disorder compromised the person. For example, we could modify the zygote's NF1 mutation, amplify expression of wildtype allele or use the occurrence of an NF1 somatic mutation as a trigger to remove the affected cell through induced apoptosis.

Many factors other than the NF1 locus or the latter's protein product, Neurofibromin (Nfn), might or can influence Cnf development, such as mast cells, ${ }^{3}$ collagen deposition ${ }^{4}$ and skin adnexae. ${ }^{5}$ Rice, et $\mathrm{al}^{2}$ makes a clear case for cell-cell cooperativity in NF1 syndrome skin potentially contributing to the development of NF1 diploinsufficiency. Terminal sensory axons in the skin are not always associated with other skin components (sweat glands, sebaceous glands, sweat ducts, vascular bundles, etc.). But, when they are, SCs may be dislodged from the involved nerve and proliferate according to new schedules. Such cell divisions afford new opportunities for the occurrence of SC NF1 somatic mutations, ultimately affording both NF1 haploinsufficient SC and NF1 diploinsufficient SC accumulations, in turn providing a cellular and intercellular conglomeration that either anticipates or represents an early-stage cNF. The overall point is that something about NF1 haploinsufficient cellular cooperativity affords the opportunity for, or actually triggers, NF1 somatic mutations. ${ }^{6,7}$

As one peruses the natural history of the NF1 syndrome at the cellular level, recurrent NF1 diploinsufficiency, that is, recurrent NF1 somatic mutation, occurs very frequently 
in multiple types of tissue, including that of the central nervous system, the peripheral nervous system, the skin, the skeleton, stem cells, endocrine glands, the vascular system, the pulmonary parenchyma, etc. In a seventh-decade NF1 adult, thousands of somatic mutations may have occurred. Exactly why this happens has escaped clarification, but these somatic mutations can be usurped or obviated nonetheless, as suggested herein.

Recently, a significant portion of medical genetics clinical research has shifted from focusing on a disorder's natural history to genetic modification, which, for example, might convert a genetic mutation "back" to the normal (i.e., wildtype allele). Respecting this general type of reasoning, it seems that the NF1 syndromefeatures (sensu strictu) could be prevented early on through genetic manipulation. Gene editinghas garnered the most interest, using deoxyribonucleic acid (DNA)-editing substances such as CRISPR/Cas9. ${ }^{8}$ The restorative molecule is introduced into each of the organism's cell nuclei, the DNA region of interest identified and that region modified from the mutant structure to a wildtype allele. ${ }^{9,10}$ However, although CRISPR/Cas9 cell-by-cell gene editing has substantial potential benefits, it is fraught with technical, political and ethical problems.

Increasing WT NF1 gene expression, especially cogent when the initial (germinal or zygotic) genetic change involves a whole gene deletion, involves increasing the WT allele's protein production to more than is usual or ordinary for the WT allele. However, one wonders about increasing the "activity" of Nfn in all cells, since the NF1 gene locus might normally be silent or quiescent in certain cell types. In cells in which it is not ordinary, NF1 gene expression might have serious negative repercussions. For the NF1 gene (locus), it is not clear that both alleles are equally expressed. Nor is it clear whether the monoallelic protein product functions on its own as a monomer or pairs as a dimer; and, if it is a dimer, whether the two parts derive from the same or different alleles.

Immediate removal of NF1 diploinsufficient cells is probably the safest genetic treatment approach for interfering with progression of the disorder by imposing a penalty for a particular development within the cell. What I have in mind here is a molecule constructed like, and emulating, a virus homologue or paralogue. This molecular construct would occupy the nucleus in each of the NF1 person's cells and has two critical abilities: 1) monitoring the long arm of Chromosome 17 to sense that the NF1 wildtype allele is present; 2) triggering initiation of apoptosis in the event of loss of the NF1 wildtype allele. In this way, any cell that converts from NF1 haploinsufficiency to NF1 diploinsufficiency will be shed immediately from the person through apoptosis. If the NF1 wildtype allele realizes an intragenic mutation or whole gene deletion, the monitoring system activates cell-specific apoptosis. None of the NF1 person's cells would be able to survive the change from NF1 haploinsufficiency to NF1 diploinsufficiency.

\section{REFERENCES}

1. Riccardi VM. Neurofibromatosis type 1 is a disorder of dysplasia: The importance of distinguishing features, consequences, and complications. Birth Defects Res A Clin Mol Teratol. 2010; 88: 9-14. doi: 10.1002/bdra.20616

2. Rice FL, Houk G, Wymer JP, et al. The evolution and multimolecular properties of NF1 cutaneous neurofibromas originating from C-fiber sensory endings and terminal Schwann cells at normal sites of sensory terminations in the skin. PLoS One. 2019; 14: e0216527. doi: 10.1371/journal.pone.0216527

3. Riccardi VM. Ketotifen suppression of NF1 neurofibroma growth over 30 years. Am J Med Genet A. 2015; 167(7): 1570-1577. doi: 10.1002/ajmg.a.37045

4. Jaakkola S, Peltonen J, Riccardi V, Chu ML, Uitto J. Type 1 neurofibromatosis: Selective expression of extracellular matrix genes by Schwann cells, perineurial cells, and fibroblasts in mixed cultures. J Clin Invest. 1989; 84: 253-261. doi: 10.1172/JCI114148

5. Amoh Y, Li L, Campillo R, et al. Implanted hair follicle stem cells form Schwann cells that support repair of severed peripheral nerves. Proc Nat Acad Sci U S A. 2005; 102: 17734-17738. doi: $10.1073 /$ pnas.0508440102

6. Tucker T, Riccardi VM, Brown C, et al. S100B and neurofibromin immunostaining and $\mathrm{X}$-inactivation patterns of laser microdissected cells indicate a multicellular origin of some NF1-associated neurofibromas. J Neurosci Res. 2011; 89: 1451-160. doi: $10.1002 /$ jnr.22654

7. Riccardi VM. Translational genetics and genomics: The fundamental nature of NF1 neurofibromas. J Transl Genet Genom. 2017; 1: 1-12.

8. Suzuki K, Tsunekawa Y, Hernandez-Benitez R, et al. In vivo genome editing via CRISPR/Cas9 mediated homologyindependent targeted integration. Nature. 2016; 540: 144-149. doi: $10.1038 /$ nature20565

9. Zhang Y, Long C, Li H, et al. CRISPR-Cpf1 correction of muscular dystrophy mutations in human cardiomyocytes and mice. Science Advances. 2017; 3: e1602814. doi: 10.1126/sciadv.1602814

10. Matharu N, Rattanasopha S, Tamura S, et al. CRISPR-mediated activation of a promoter or enhancer rescues obesity caused by haploinsufficiency. Science. 2019; 363(6424): eaau0629. doi: $10.1126 /$ science.aau0629 